\title{
Produção estacional de embriões in vivo em vacas da raça Gir (Bos indicus) na região sudeste (clima tropical), Brasil
}

\author{
Seasonal embryos production from Gir dairy cows (Bos indicus), \\ in southeast region (tropical climate), Brazil
}

Antonio Prieto Dourado, ${ }^{*, * *}$ Rodolpho de AlmeidaTorres Filho, ${ }^{* *}$ Elyzabeth da Cruz Cardoso, ${ }^{* *}$ Letícia Del Penho Sinedino, ${ }^{*}$ Bruna Teixeira Gerhardt, ${ }^{*}$ Isis Lustosa Goulard, ${ }^{*}$ Luiz Altamiro Garcia Nogueira*,***

\begin{abstract}
Resumo
O objetivo do presente estudo foi comparar o desempenho da ovulação múltipla (SOV) seguida da fertilização in vivo em vacas adultas puras da raça Gir Leiteiro (Bos taurus indicus), em duas diferentes condições climáticas da região Sudeste do Brasil. As SOV, realizadas entre os anos de 1997 e 2010, foram agrupadas nos meses de novembro, dezembro, janeiro e fevereiro (caracterizados como verão) e nos meses de maio, junho, julho e agosto (caracterizados como inverno). As informações avaliadas neste estudo consistiram de resultados de 180 sessões de SOV realizadas em 71 doadoras. Foram submetidas à fertilização in vivo com sêmen convencional de 34 touros puros da mesma raça e fertilidade conhecida. Foi recuperado o total de 1406 estruturas e foram produzidos 797 embriões viáveis que se destinavam a inovulações em rebanhos comerciais. As médias das respostas obtidas por cada sessão de SOV no inverno e verão foram respectivamente: totais de estruturas recuperadas (8,5 vs $7,3)$, embriões viáveis $(4,8$ vs 4,0$)$, embriões degenerados $(2,1$ vs 2,5$)$ e estruturas não fecundadas $(1,5$ vs 0,7$)$; apenas esta última resposta apresentou diferença significativa $(p<0,05)$ entre as estações. Os percentuais médios obtidos por sessão de SOV nas mesmas estações foram, respectivamente, 57,6 e 58,5 \% para embriões viáveis, 22,9 e 31,7\% para embriões degenerados e 19,4 e 9,8 para estruturas não fecundadas. Considerando-se as proporcionalidades, apenas as percentagens de embriões viáveis não apresentaram diferença significativa $(p<0,05)$. Conclui-se que na Região Sudeste, vacas puras da raça Gir foram capazes de produzir o mesmo número de embriões viáveis, tanto no inverno como no verão. O percentual de embriões viáveis sobre o total de estruturas recuperadas também não diferiu entre estas estações. Os percentuais de embriões degenerados e estruturas não fecundados fazem supor que o desempenho da transferência de embriões in vivo possa ser otimizado na região.
\end{abstract}

Palavras-chave: Bos indicus, SOV, índices reprodutivos, produção sazonal, embriões.

\begin{abstract}
The objective of this study was to compare the results of superovulations (SOV) followed by in vivo fertilization of dairy Gir cows (Bos taurus indicus) during two different seasons in Southeast Brazil. All super-ovulations between 1997 and 2010 were grouped according to the season; summer (November, Dezember, January and February) and winter (May, June, July and August). The results consisted of a total of 180 SOV in 71 cows submitted to in vivo fertilization using 34 fertile bulls of the same breed. A total of 1406 structures were recovered among them 766 viable embryos were transferred to the recipient cows. The mean results after each SOV according to the season (summer and winter) were 8.5 and 7.3 for total recovered structures, 4.8 and 4.0 viables embryos, 2.0 and 2.5 degenerate embryos and 1.5 and 0.7 for unfertile structures, respectively. Just the number of unfertilized structures were statistically different $(p<0.05)$ between seasons. The average percentage of viable embryos in the recovered structures after SOV in summer and winter was (57.6 and 58.5\%), of degenerate embryos (22.9 and $31.7 \%)$ and of unfertilized structures (19.4 and 9.8\%) respectively. Just the percentage of viable embryos did not differ statistically ( $p<0.05)$ according to the season. In conclusion dairy Gir cows in Southeast Brazil were able to produce the same number of viable embryos, both during the winter and summer and the percentage of viable embryos over the total number of recovered structures did not differ between the seasons. The percentage of degenerate embryos and of unfertilized structures suport that performance of embryo transfer can be otimizated in this region.
\end{abstract}

Keywords: Bos indicus, SOV, reprodutive índex, seasonal production, embryos.

\footnotetext{
* Programa de Pós-Graduação em Medicina Veterinária (Clínica e Reprodução Anima). Universidade Federal Fluminense, Niterói, Rio de Janeiro, Brasil.

** Departamento de Zootecnia, Faculdade de Veterinária, Universidade Federal Fluminense, Niterói, Rio de Janeiro, Brasil.

*** Departamento de Patologia e Clínica, Faculdade de Veterinária, Universidade Federal Fluminense, Niterói, Rio de Janeiro, Brasil.

Autor para correspondência. E-mail: prietodourado@hotmail.com.
} 


\section{Introdução}

A SOV seguida da transferência de embriões continua sendo considerada um dos métodos mais práticos para incrementar o número de produtos nascidos de vacas de alto valor genético, tanto em rebanhos de leite como de corte. Possibilitando o transporte de embriões congelados entre rebanhos, quando comparado ao trânsito de matrizes e reprodutores vivos, reduz o custo e o risco epidemiológico de deslocamento de animais (Neves et al., 2010).

Entretanto, com a difusão desta biotecnologia, a literatura nacional e internacional passou a relatar uma elevada variabilidade das respostas à superovulação. Vários fatores têm influenciado tais respostas: estação do ano, precipitação pluviométrica, fotoperíodo, disponibilidade nutricional, tratamento superovulatório e interações individuais, de linhagens e raciais (Armstrong, 1994; Mapletoft et al. 2002; Torres Junior, 2007; Pontes, 2010).

Revisando as correlações do estresse térmico de verão e a função reprodutiva em vacas taurinas, Thatcher et al. (2010) verificaram que os períodos sazonais de redução da fertilidade foram associados ao aumento da temperatura e umidade do ar. A elevação da temperatura corporal deprime a manifestação do estro, a função ovariana, o desenvolvimento folicular, a competência oocitária e o desenvolvimento do embrião. $\mathrm{Na}$ estação quente, curtos períodos de hipertemia comprometeram a fertilidade e mesmo com posterior resfriamento.

A baixa eficiência da produção de embriões associada à superovulação no período quente do ano, frequentemente é atribuída à: redução do número de embriões viáveis, não responsividade aos protocolos de superovulação, baixa taxa de fertilização e qualidade dos embriões (Hansen et al., 2001).

Até o momento não se sabe exatamente em que estágio do desenvolvimento folicular o efeito do estresse calórico é capaz de atuar. Thatcher et al. (2010) recomendaram que, analogamente aos efeitos sobre os testículos, um intervalo de tempo de 45 dias seria requerido para completar um novo ciclo da gametogênese, antes da completa restauração da qualidade dos gametas pós-estresse calórico. Assim os ovários também necessitariam de um tempo para a restauração completa de sua fertilidade durante o outono.

Na região Sudeste do Brasil, Santos (2001) e Borges (2004) estudaram a dinâmica folicular e a duração dos ciclos estrais em vacas da raça Gir mantidas em condições nutricionais satisfatórias. Ambos os autores concluíram que não ocorreram alterações estacionais significativas no perfil do estro. Peixoto (2007) e Pontes et al. (2010) consideraram a SOV pouco avaliada estatisticamente no Brasil em seus aspectos econômicos, ambientais e genéticos, principalmente considerando que grande parte do efetivo bovino nestes programas era como ainda hoje, composto de rebanhos de raças zebuínas com variada distribuição geográfica.

O objetivo do presente estudo foi avaliar o desempenho de vacas da raça Gir superovuladas em condições climáticas tropicais de verão e inverno da região Sudeste do Brasil.

\section{Material e métodos}

As informações utilizadas no presente estudo foram resultado de um programa de reprodução assistida, visando a multiplicação de animais puros da raça Gir (linhagem leiteira) entre os anos de
1997 e 2010. O programa envolveu 71 doadoras, inseminadas com sêmen convencional de 37 touros, mantidas em três propriedades rurais próximas à central de transferência de embriões.

Os protocolos de superovulação foram conduzidos pela Gertec Embriões Ltda., em sua Central de TE (fazenda e laboratório) localizada no município de São José do Barreiro, no norte do estado de São Paulo (22 $38^{\prime}$ S; 44 $34^{\prime}$ W). Tanto os rebanhos como o laboratório encontram-se em uma condição fisiográfica típica do Médio Vale do Paraíba (clima tropical de altitude), que igualmente abrange a microrregião do sul do estado do Rio de Janeiro, com média de $500 \mathrm{~m}$ acima do nível do mar.

Os dados meteorológicos dos períodos foram obtidos do Relatório de Dados Mensais por Ano das Estações do Instituto Nacional de Meteorologia - INEMET (2011).

Os dados foram agrupados com referência aos meses de novembro, dezembro, janeiro e fevereiro (caracterizados como verão) e aos meses de maio, junho, julho e agosto (caracterizados como inverno).

O cálculo do índice de temperatura e umidade (ITU) foi baseado na formulação proposta por Kelly e Bond (1971), porém com base nas médias das temperaturas máximas ou mínimas do ar e na umidade relativa verificadas nos períodos citados:

$$
\text { ITU }=0,8 \times \text { TBS + URA }(\text { TBS }-143) / 100+46,5 \text { onde: }
$$

TBS - temperatura média máxima ou mínima do ar medida com termômetro de bulbo seco e URA - umidade relativa do ar.

As variáveis climáticas que caracterizaram a região e o período onde os rebanhos da raça Gir eram criados encontram-se no quadro 1.

Nos rebanhos de origem das doadoras e na Central de TE predominam os sistemas adaptados de rotação de pastagens tropicais nativas e melhoradas. A suplementação mineral é feita durante todo ano e a de concentrados e volumosos (cana, napier e silagens de milho e/ou mistas), predominantemente no período seco de inverno, quando necessário para manter o escore de condição corporal das matrizes, adequado à reprodução.

As doadoras encaminhadas para o programa obedeceram a um intervalo mínimo de 60 dias entre os protocolos SOV. O protocolo de superovulação consistiu na administração do hormônio FSH (Pluset $^{\circledR}$, Hertape Calier, MG, Brasil) na dosagem total de 350 UI, fracionada em quatro dosagens decrescentes e em duas aplicações diárias iniciado no dia 8 indo até o dia 12 após a manifestação do cio base.

Foram realizadas três inseminações artificiais (IA) em um período de $30 \mathrm{~h}$ em cada doadora que iniciou aproximadamente 14 horas após o cio ser detectado.

A coleta das estruturas ocorreu sete dias após a IA, pelo método não cirúrgico.

Os embriões foram classificados quanto ao estágio de desenvolvimento e qualidade conforme a IETS. Posteriormente foram envasados individualmente e transferidos a fresco ou criopreservados.

As variáveis respostas avaliadas foram calculadas por sessão de ovulação múltipla induzida, usando-se os procedimentos FREQ PROC e M EANS PROC SAS SISTEM (1994) e a comparação de médias pelo teste de Tukey (Kruskal-Wallis) ao nível de 5\% de probabilidade $(p<0,05)$. 
Quadro 1: Médias de temperaturas, máximas e mínimas mensais, máximas e mínimas absolutas mensais e diárias com respectivos índices de temperatura e umidade, umidades relativas do ar e precipitações pluviométricas, nos períodos de inverno e verão, entre os anos de 1997 e 2010, na região do Vale do Paraíba, Região Sudeste

\begin{tabular}{|c|c|c|}
\hline Variáveis climáticas & Inverno & Verão \\
\hline Temperatura Máxima Média Mensal $\left({ }^{\circ} \mathrm{C}\right)$ & $25,3 \pm 1,5$ & $29,9 \pm 1,6$ \\
\hline ITU Máxima Média Mensal & 75,0 & 82,6 \\
\hline Temperatura Máxima Absoluta Mensal $\left({ }^{\circ} \mathrm{C}\right)$ & $30,3 \pm 1,9$ & $34,7 \pm 1,2$ \\
\hline ITU Máxima Absoluta Mensal & 82,7 & 90,2 \\
\hline Temperatura Máxima Registrada/mês $\left({ }^{\circ} \mathrm{C}\right)$ & $\begin{array}{c}35,2 \\
\text { (agosto/2006) }\end{array}$ & $\begin{array}{c}38,0 \\
\text { (jan/2008) }\end{array}$ \\
\hline ITU Maximo Registrado/mês & 89,5 & 96,1 \\
\hline Temperatura Mínima Média Mensal $\left({ }^{\circ} \mathrm{C}\right)$ & $13,6 \pm 1,4$ & $20,0 \pm 1,1$ \\
\hline ITU Mínima Média Mensal & 56,8 & 66,9 \\
\hline Temperatura Mínima Absoluta Mensal $\left({ }^{\circ} \mathrm{C}\right)$ & $8,4 \pm 2,0$ & $17,0 \pm 1,9$ \\
\hline ITU da Temperatura Mínima Absoluta & 62,2 & 48,8 \\
\hline Temperatura Mínima Registrada $\left({ }^{\circ} \mathrm{C}\right)$ & $\begin{array}{c}3,0 \\
\text { (julho/2000) } \\
\end{array}$ & $\begin{array}{c}12,0 \\
\text { (Novembro/1999) } \\
\end{array}$ \\
\hline ITU Mínima Registrada/mês & 40,3 & 54,3 \\
\hline Umidade Relativa Ar Mensal Média (\%) & $74,8 \pm 4,5$ & $78,0 \pm 3,5$ \\
\hline Precipitação Pluviométrica Acumulada Mensal média $\left(\mathrm{mm}^{3}\right)$ & $30,2 \pm 24,1$ & $239,0 \pm 111,7$ \\
\hline Precipitação Pluviométrica Acumulada anual média $\left(\mathrm{mm}^{3}\right)$ & $1.594 \pm 350,0$ & \\
\hline
\end{tabular}

Fonte: INMET (2011).

As respostas avaliadas foram as seguintes: número total de estruturas recuperadas, total de embriões viáveis, total de estruturas degeneradas, total de estruturas não fecundadas, percentual de embriões viáveis, percentual de estruturas degeneradas e percentual de estruturas não fecundadas.

\section{Resultados}

Os resultados relatados no presente estudo corresponderam a 180 sessões SOV que totalizaram: 1406 estruturas recuperadas, 792 de embriões classificados como viáveis à transferência de embriões (TE), 416 embriões degenerados e 198 oócitos que não foram fecundados. Os valores médios das respostas de desempenho da SOV por cada época do ano encontramse na Tabela 1.

Os porcentuais de cada tipo de estrutura, em relação ao número total de estruturas recuperadas em cada sessão de SOV são apresentados na Tabela 2.

No presente estudo de desempenho da ovulação múltipla, não foram detectadas diferenças $(p<0,05)$ para médias das seguintes respostas: estruturas recuperadas pós flushing/SOV; embriões viáveis para transferência/SOV; embriões degenerados/SOV.

Nos parâmetros de desempenho que dizem respeito à proporcionalidade, o porcentual de estruturas não fecundados, ou seja, de oócitos recuperados no inverno, foi superior $(p<0,05)$ em relação ao verão, o que caracterizou o efeito estacional de competência oocitária. O percentual de embriões degenerados sobre o total de estruturas recuperadas foi maior no verão $(p<0,05)$, o que também caracterizou estacionalidade na qualidade dos embriões produzidos.
Tabela 1: Totais de sessões de ovulações múltiplas seguidas das médias e desvios-padrões das respostas por sessão SOV, de estruturas recuperadas, embriões viáveis, embriões degenerados, estruturas não fecundadas e nas estações climáticas de inverno e verão

\begin{tabular}{lccc}
\hline \multirow{2}{*}{ Variáveis } & \multicolumn{2}{c}{ Estações Climáticas } & \multirow{2}{*}{ Total Geral } \\
\cline { 2 - 3 } & Inverno & Verão & \\
\hline Total de sessões de SOV & 87 & 93 & 180 \\
Estruturas recuperadas/SOV & $8,5^{\mathrm{A}} \pm 6,1$ & $7,3^{\mathrm{A}} \pm 4,7$ & $7,9 \pm 5,5$ \\
Embriões viáveis/SOV & $4,8^{\mathrm{A}} \pm 4,0$ & $4,0^{\mathrm{A}} \pm 3,6$ & $4,4 \pm 3,8$ \\
Embriões degenerados/SOV & $2,1^{\mathrm{A}} \pm 2,9$ & $2,5^{\mathrm{A}} \pm 3,2$ & $2,3 \pm 3,1$ \\
Estruturas não fecundadas/SOV & $1,5^{\mathrm{B}} \pm 3,4$ & $0,7^{\mathrm{A}} \pm 2,4$ & $1,1 \pm 2,9$ \\
\hline
\end{tabular}

* Médias na mesma linha, seguidas por letras diferentes diferiram significativamente $(p<0,05)$.

Tabela 2: Totais de sessões de ovulações múltiplas seguidas das médias e desvios-padrões das respostas/sessão SOV: porcentagem de embriões viáveis (PEV), porcentagem de embriões degenerados (PED) e porcentagem de estruturas não fecundadas (PENF), nas estações climáticas e inverno e verão

\begin{tabular}{cccc}
\hline \multirow{2}{*}{ Variáveis } & \multicolumn{2}{c}{ Estações Climáticas } & \multirow{2}{*}{ Total Geral } \\
\cline { 2 - 3 } & Inverno & Verão & \\
\hline Totais de sessões de SOV & 87 & 93 & 180 \\
PEV (\%) & $57,6^{A} \pm 32,2$ & $58,5^{A} \pm 34,2$ & $58,0 \pm 33,2$ \\
PED (\%) & $22,9^{A} \pm 23,7$ & $31,7^{\mathrm{B}} \pm 30,9$ & $27,3 \pm 27,9$ \\
PENF (\%) & $19,4^{\mathrm{B}} \pm 33,0$ & $9,80^{\mathrm{A}} \pm 24,6$ & $14,6 \pm 29,3$ \\
\% de estruturas fecundadas & 80,6 & 90,2 & \\
\hline
\end{tabular}




\section{Discussão}

As médias de estruturas recuperadas por SOV nas vacas da raça Gir não diferiram $(p<0,05)$ nos períodos climáticos de inverno e verão. A média geral obtida $(7,9 \pm 5,5)$ coincide com o verificado por Peixoto et al. (2007), que obtiveram média de 7,3 $\pm 5,9$ estruturas em 48 SOV realizadas em um período de 10 anos, em vacas da raça Gir oriundas de diversas regiões do Brasil. Quando comparada com as outras raças, o total de estruturas recuperadas $(7,9 \pm 5,5)$ nesta raça, foi inferior às raças Guzerá $(9,9 \pm 7,9)$ e Nelore $(10,2 \pm 7,8)$. Outro estudo em novilhas Guzerá que também não apontou diferença sazonal, apresentou médias superiores, entre 17 e 20 estruturas coletadas (Gama Filho et al. (2007). Nossos resultados superaram a pesquisa comparativa de ovulação múltipla na raça Gir, quando avaliadas três doses de FSH (300; 400 e 500 UI), onde as médias de estruturas recuperadas foram de 5,0; 5,5 e 2,9 respectivamente (Prado et al., 2007).

Anteriormente, também na raça Nelore, Barros e Nogueira (2004) obtiveram a média geral de 12,4 estruturas recuperadas por SOV, ao avaliarem diferentes protocolos hormonais e concentrações espermáticas na inseminação artificial.

Num estudo com diversas raças zebuínas, a raça Gir foi a que disponibilizou menos estruturas, independentemente da estação climática (Peixoto, 2006). Embora segundo o mesmo autor, o mês em que a SOV foi realizada possa ser um dos fatores que influenciam o total de estruturas recuperadas, considerandose o maior tamanho da amostra e a menor variabilidade das respostas do presente estudo, supomos que esta variável não foi influenciada pelas estações climáticas da região.

As médias de embriões viáveis e o seu porcentual sobre o total de embriões recuperados por SOV nos animais estudados, também não diferiram $(p>0,05)$ entre os períodos climáticos avaliados. A média geral de embriões viáveis em todo o período foi 4,4 , sendo superior às médias obtidas por Prado et al. (2007), iguais a 1,7 e 3,4 .

Os porcentuais médios de embriões viáveis recuperados por SOV em cada período climáticos avaliado não diferiram entre si, mostrando a não constatação de efeito sazonal desta variável, cuja média geral foi $58,0 \%$, situada entre os valores médios de 34,7 e 61,3 \% citados na mesma raça por Prado et al. (2007).

No estudo em que Peixoto et al. (2006) superovularam vacas de diversas raças zebuínas, a média total de embriões viáveis recuperados foi de 5,7 , que representa um embrião ou $20 \%$ de rendimento superior ao verificado em nosso estudo. Novamente os valores médios foram semelhantes e intermediários nas raças Guzerá $(5,7)$ e Nelore $(5,1)$, mais elevada para a raça Brahman $(7,3)$ e menor para a Gir $(4,1)$. Entretanto, os percentuais de embriões viáveis, cuja média geral foi de $51,1 \%$, não seguiram as mesmas ordens de grandeza e tiveram a seguinte distribuição: para a raça Brahman, 53,2\%; a Gir 56,6\%, a Guzerá $57,0 \%$ e a Nelore $49,9 \%$.

Fonseca et al. (2001) obtiveram a média de 5,2 embriões viáveis por SOV (Graus 1 e 2 em vacas zebuínas, sendo que corresponderam a $95 \%$ dos totais de embriões coletados. Atentese que no cálculo deste porcentual não foram considerados os oócitos que não foram fecundados.
Em outros trabalhos empregando fêmeas da raça Nelore superovuladas, foram produzidos 5,2 embriões viáveis (Visintin et al. 1999) e 6,7 embriões viáveis (Pontes, 2009). Valores mais altos (9,5 e 8,7 embriões viáveis) também foram obtidos nesta raça, em ensaios que apresentaram as taxas de viabilidade de $76,0 \%$ e 69,8 \% respectivamente (Barros e Nogueira, 2004).

Em estudo realizado na Califórnia (USA), os autores atribuíram ao efeito deletério de estresse calórico de verão, a redução quantitativa $(p=0,08)$ de embriões viáveis recuperados, que no inverno foi de 3,4 e no verão 1,7 embriões por SOV (Chebel et al. 2008).

No Brasil, em rebanho de estação experimental, Bényei e Barros (2000) conseguiram a média de 6,0 embriões viáveis com vacas Holandesas mantidas em clima árido. Payton et al. (2004) afirmaram que as estruturas quando ainda nos folículos antrais, são susceptíveis aos efeitos diretos da elevação da temperatura corporal e tal fato poderia em parte estar reduzindo a fertilidade destes animais, o que também já havia sido reportado por Wolfenson et al. (1995). Tal fato não ocorreu no presente estudo, provavelmente pela melhor adaptação da raça Gir ao clima da região Sudeste.

Contrariamente, Gama Filho et al. (2007) constataram efeito sazonal em novilhas Guzerá, tanto para a média de embriões viáveis ( 7 no verão e 18 no inverno) como em seus respectivos porcentuais (41,2 e 90,0\%). As condições de estresse severo e moderado foram atingidas no pico destas estações na microrregião de baixada, ao norte do estado do Rio de Janeiro.

Neste estudo, a média geral de 2,3 embriões degenerados por SOV no conjunto dos períodos climáticos está entre os valores médios observados nos períodos de verão e inverno para o desempenho das vacas da raça Gir e não apresentaram diferença significativa entre as estações. Gama Filho et al. (2007) também obtiveram média de 2 embriões não viáveis no inverno ou no verão. Considerando que correspondem a cerca de $10 \%$ do total recuperado, os autores acreditam que os embriões oriundos de vacas da raça Guzerá foram termorresistentes ao ITU do verão (94) e aos picos de temperatura corporal captada $\left(40,5^{\circ} \mathrm{C}\right)$.

A média de degeneração de embriões no rebanho da raça Holandesa, reportado por Bényei e Barros (2000) no Nordeste do Brasil, foi de 5,1 \pm 4,8, média considerada alta; porém também foi alto o número de embriões viáveis obtidos com vacas da raça Holandesa $(6,0)$, mantidas em clima árido (Rivera e Ransen, 2001).

No presente estudo, as porcentagens médias de embriões degenerados sobre o total de estruturas recuperadas por SOV no período climático do verão $(31,7 \%)$ foi maior $(p<0,05)$ do que no período de inverno (22,9\%). As respostas demonstraram efeito de sazonalidade, além de apresentar coeficiente de variação próximo a $100 \%$.

Períodos próximos à ovulação até o terceiro dia do desenvolvimento embrionário são mais susceptíveis ao estresse térmico (período termossensivel), quando temperaturas elevadas podem reduzir a proporção de embriões em desenvolvimento. Tais efeitos são reduzidos conforme os embriões se tornam mais desenvolvidos entre o terceiro e oitavo dia pós IA (Early et al., 1995). Experimentalmente, Payton et al. (2004) induziram a 
degeneração de mórula e blastocistos quando a temperatura de cultivo atingiu $41^{\circ} \mathrm{C}$ por mais de 6 horas.

No presente estudo não chegou a ocorrer temperatura equivalente, onde a máxima média mensal foi $34,5^{\circ} \mathrm{C}$ e a máxima registrada no verão foi $38,0^{\circ} \mathrm{C}$. Entretanto, associado a tais temperaturas, o período de alta umidade relativa do ar que ocorreu no verão (78\%) geraram ITU de 90,2 até a máxima registrada de 96,1. Tais magnitudes de ITU são citadas como severo (Armstrong, 1994) e perigoso (Oliveira et al., 2006). Essas comprovações talvez possam explicar os resultados do presente trabalho.

Diante das mudanças climáticas globais e dificuldades em reduzir o impacto sobre a fertilidade de vacas leiteiras de alta produção, Hansen et al. (2001) sugeriram que, quando possível, os programas de produção de embriões deveriam ser transferidos para períodos do ano que não impusessem esta condição. Concordamos com aqueles pesquisadores que consideram esta medida pouco prática para programas de larga escala; entretanto, nas atuais condições, além da adequação do manejo (Pires, 2010), poderiam ser evitados nas doadoras de TE, aqueles meses cuja ITU atinja recordes regionais. Exemplo deste cuidado quanto ao uso da inseminação artificial, é adotado em alguns rebanhos leiteiros taurinos puros e mestiços da Região Sudeste do Brasil.

A contagem de estruturas não fecundadas foi obtida da leitura direta do lavado uterino após a SOV, inseminação e recuperação das estruturas. Diz respeito principalmente à competência oocitária e espermática em iniciar o desenvolvimento de um embrião, que no estágio de mórula ou blastocisto compacto apresentou condição ideal para sua transferência. Em termos objetivos é o principal parâmetro que avalia um conjunto de etapas, desde os efeitos anteriores ocorridos no desenvolvimento folicular, na ovulação e na fecundação.

Neste estudo, a média de estruturas não fecundadas e recuperadas no período climático de verão $(0,7)$ foi inferior $(p<0,05)$ ao que foi recuperado durante o inverno $(1,5)$. A porcentagem de estruturas não fecundadas expressa a proporcionalidade sobre o total das estruturas recuperadas. Durante o período climático de inverno este percentual foi 19,4 $\%$, e superior $(p<0,05)$ em relação ao período de verão $(9,8 \%)$. Podemos dizer que a taxa de concepção pós SOV no verão foi cerca do dobro em relação ao inverno.

Estes porcentuais foram relativamente mais baixos do que os obtidos experimentalmente em vacas da raça Gir, quando se variou a dosagem de FSH exógeno empregado na SOV; talvez esse motivo justifique a qualidade dos oócitos e a variação entre 19 e $51 \%$ de não fecundados obtidos por Prado et al. (2007).

Um estudo do efeito das quatro estações climáticas sobre a produção de embriões em vacas da raça Nelore superovuladas na região Sul do Brasil, não encontrou diferença entre os valores absolutos ou porcentuais de não fertilizados nas estações de inverno e verão (Albuquerque, 2007).

Entretanto, o efeito deletério do verão sobre a produção de embriões da raça Guzerá pela SOV manifestou-se pelo número de oócitos não fecundados no verão (47\% - 8/17) segundo Gama Filho et al. (2007).

Enquanto em $B$. indicus as informações são escassas, em $B$. taurus são por vezes contraditórias e, além de múltiplas, as fontes de variação apresentam alta variabilidade.
$\mathrm{Na}$ análise retrospectiva de um programa reprodutivo turco, Sonmez et al. (2005) verificaram que as vacas no verão tiveram as mais baixas taxas de concepção $(47,9 \%)$ em relação ao inverno $(73,3)$ e à primavera $(78,9 \%)$ e que talvez tenha ocorrido algum efeito residual sobre o outono $(68, \%)$.

Na Arábia Saudita, que também apresenta clima quente e seco durante verão, RYAN et al. (1993) conduziram experimento em TE com vacas da raça Holandesas: enquanto a viabilidade dos embriões recuperados entre o dia 7 e o dia 14 reduziu de $59 \%$ para $27 \%$ no verão, as porcentagens de estruturas não fecundadas não foram afetadas $(p<0,05)$ em qualquer estação. A competência oocitaria foi susceptível aos efeitos da elevada temperatura ambiental $\left(41^{\circ} \mathrm{C}\right)$, desde o estágio de vesícula germinal no folículo antral (Payton et al., 2004) ou afetada negativamente na dinâmica folicular, na qualidade dos oócitos produzidos e sua sobrevivência e competência em chegar a ser fertilizado (EALY et al., 1995; HANSEN e ARECHIGA, 1999).

A mortalidade de embriões coletados com idade de 6 e 14 dias (RYAN et al. 1993) produzidos in vivo (SOV) com vacas da raça Holandesas mantidas em clima quente e seco (árido), não apresentaram diferenças significativas estacionais nas taxas de recuperação de embriões e oócitos no sétimo dia após o estro, porém houve perdas significativas no número de embriões viáveis em relação ao $14^{\circ}$ dia durante o verão (59\% e $\left.27 \%\right)$ mas não no inverno (52\% e $60 \%$ ).

Rutledge et al. (1999) e Al-Katanani et al. (2002) também confirmaram efeitos deletérios de verão, que afetaram a capacidade de maturação oocitária ou fertilização ou o desenvolvimento dos zigotos até a fase blastocistos, de forma que a qualidade das estruturas recuperadas foram inferiores em relação ao inverno.

No Brasil, taurinos leiteiros da raça Mantiqueira aclimatados à região Sudeste não apresentaram estacionalidade qualitativa ou quantitativa na produção de embriões por SOV (Alvarez, 2005), porém vacas da raça Nelore mantidas na região Sul, quando superovuladas nas quatro estações, apresentaram no verão e inverno, médias inferiores $(p<0,05)$ para o número de estruturas recuperadas e o número de embriões viáveis, mas não para os números e porcentagem de estruturas não fecundadas. Assim sendo, o autor sugeriu que a realização da TE, com zebuínos no Noroeste do Paraná fosse realizada na primavera e outono (ALBUQUERQUE, 2007).

No presente estudo, o efeito estacional de verão aumentou as taxas de fertilização dos oócitos, mas também aumentou as taxas de degeneração de embriões; portanto, o número total de embriões viáveis foi compensado pela diferença de desempenho em cada estação.

Segundo Hansen et al. (2001) existem algumas medidas que podem ser tomadas para minimizar os efeitos deletérios do estresse calórico sobre a reprodução: os protocolos de sincronização de onda folicular e TE em tempo fixo associados à facilitação do manejo e conforto animal. Foram sugeridos também: a escolha de fêmeas com maior tolerância ao calor para os programas reprodutivos conduzidos durante os meses mais quentes e a longo prazo, o desenvolvimento de fármacos embriotrópicos ou antioxidantes que impeçam ou reduzam a magnitude dos efeitos deletérios da hipertermia causada pelo estresse calórico sobre o desenvolvimento embrionário. 
Embora haja unanimidade quanto à maior tolerância ao calor, dos zebuínos em relação aos taurinos, devido aos atributos anatomofisiológicos que dispõem para dissipação e reflexão de calor, Torres Junior (2007) demonstrou que estes bovinos também sofreram estresse calórico quando sua termoneutralidade foi superada e apresentaram: taquipneia e hipertermia; efeito deletério sobre a qualidade dos oócitos aspirados; efeito residual de dissipação paulatina após a recuperação da termoneutralidade.

Baseado nos desempenhos apresentados no presente estudo, podemos supor que o incremento potencial de 9,3 pontos porcentuais, representa praticamente um embrião viável a mais $(0,9)$ para transferência ou criopreservação por sessão SOV.

\section{Referências}

ALBUQUERQUE, K.P. Resposta superovulatória, produção e qualidade de embriões e concentração de ácidos graxos de vacas suplementadas com grãos de linhaça ou canola. Tese de doutorado. Universidade Maringá. Paraná. 84 p. 2007.

AL-KATANANI, Y. M., PAULA-LOPES, F. F, AND HANSEN P, J. Effect of season and exposure to heat stress on oocyte competence in Holstein cows. Journal of Dairy Science v. 85, p. 390-396 2002. ALVAREZ, R.H., da SILVA, M.V., de CARVALHO, BINELLI, M. EFFECTS OF inbreeding on ovarian responses and embryo production from superovulated Mantiqueira breed cows. Theriogenology. v. 64, p.1669-1676. 2005.

ALVES, N.G.; PEREIRA, M.N.; COELHO, R.M. Nutrição e reprodução em vacas leiteiras. Rev. Bras. Reprod. Anim. Supl., Belo Horizonte, n. 6, p.118-124, dez. 2009. Disponível em www. cbra.org.br, visualizado em 10 março 2012.

ARMSTRONG, D.V. Heat stress interaction with shade and cooling. Journal of Dairy Science, v. 77, p. 2044-2050, 1994.

BARROS, C.M,.; NOGUEIRA, M.F.G. Superovulação em zebuínos de corte. In: Anais do 1o. Simpósio Internacional de Reprodução Animal Aplicada. Londrina, p. 212-222. 2004.

BENYEI, B.; BARROS, C.C.W.. Efeito da superovulação sobre o desempenho de bovinos doadores de embrião importados de clima temperado para clima tropical nos dois primeiros anos de adaptação. Arq. Bras. Med. Vet. Zootec., Belo Horizonte, v. 52, n. 4, Aug. 2000.

BORGES, A.M.; TORRES, C.A.A.; ROCHA JUNIOR, V.R. et al. Dinâmica follicular e momento da ovulação em vacas não lactantes das raças Gir e Nelore durante duas estações do ano. Arquivo Brasileiro de Medicina Veterinária e Zootecnia, v. 56, n. 3, p. 346354, 2004.

CHEBEL, R.C., DEMETRIO, D.G.B., METZGER, J.. Factors affecting success of embryo collection and transfer in large dairy herds. Theriogenology, v. 69, p. 98-106. 2008.

EALY, A.D.; HOWELL, J.L.; MONTERROSO, V.H.; ARECHIGA, C.F.; HANSEN, P.J. Developmental changes in sensitivity of bovine embryos to heat shock and use of antioxidants as thermoprotectants. J. Anim. Sci., v. 73, p.1401-1407. 1995.

FONSECA, J.F., SILVA FILHO, J.M., PINTO NETO, A., PALHARES, M.S. Estadios de desenvolvimento embrionário de vacas zebuínas superovuladas. Arq. Bras. Med. Vet. Zootec., v. 53, n. 6, p. 671679. 2001.

GAMA FILHO, R.V.da; FONSECA, F.A.; UENO, V.G., QUIRINO, C.R.; RAMOS, J.L.G. Sazonalidade na dinâmica folicular ovariana e produção embrionária em novilhas da raça guzerá. Braz.J. Vet. Anim. Sci., São Paulo, v. 44, n. 6, p. 422-427, 2007.

HANSEN, P.J. \& ARÉCHIGA, C.F. Strategies for managing reproduction in heat-stressed dairy cow. J. Anim. Sci. v. 77, p. 36-50, 1999.

\section{Conclusões}

Com base nos desempenhos alcançados no presente estudo podemos concluir:

- O número de embriões produzidos in vivo em vacas da raça Gir superovuladas não foi afetado pelo clima de verão e inverno sob condições tropicais.

- O porcentual de oócitos fecundados in vivo (SOV) em vacas da raça Gir superovuladas foi maior no verão.

- O percentual de embriões degenerados em vacas da raça Gir superovuladas foi menor no inverno.

HANSEN, P.J., M. DROST, M., RIVERA R.M., PAULA-LOPES, F.F. AI-KATANANIT, Y.M., KRININGER III, C.E., CHASE JR., C.C.. Adverse impact of heat stress on embryo production: causes and strategies for mitigation. Theriogenology, v. 55, p. 91-103, 2001.

INMET. 2011. Boletim agroclimatológico. Relatório de Dados Diários por Ano. Divisão de Meteorologia Aplicada - DIMAP. Brasília, DF. Brasil. Dados não publicados.

KELLY, C.F.; BOND, T.E. Bioclimatic factors and their mensurements. 1971. In: AZEVEDO, M. de; PIRES, M.F.A.; SATURNINO, H.M.; LANA, A.M.Q.; SAMPAIO, I.B.M.; MONTEIRO, J.B.N.; MORATO, L.E. Estimativa de níveis críticos superiores do índice de temperatura e umidade para vacas leiteiras $1 / 2,3 / 4$, e 7/8 Holandes-zebú em lactação. R. Bras. Zootec., v. 34, n. 6, p. 2000-2008, 2009

MAPLETOFT, R.J.; STEWARD, K.B.; ADAMS, G.P. Recent advances in the superovulation in cattle. Reprod. Nutr. Dev., v. 42, p. 601-611, 2002.

NEVES, J.P. ; MIRANDA, K.L.; TORTORELLA, R.D. Progresso científico em reprodução na primeira década de século XXI. $R$. Bras. Zootec., v. 39, p. 414-421, (suplemento especial). 2010.

OLIVEIRA, L.M.F.de, YANAGI JUNIOR, T.; FERREIRA, E.; CARVALHO, L.G.de; SILVA, M.P.da. Zoneamento bioclimático da região Sudeste do Brasil para o conforto térmico animal e humano. Eng. Agríc., Jaboticabal, v. 26, n. 3, p. 823-831, 2006.

PAYTON, R.R., ROMAR, R., COY, P., SAXTON,A.M.,LAWRENCE, J.L., LANNETT EDWARDS, J.L., Susceptibility of Bovine Germinal Vesicle-Stage Oocytes from Antral Follicles to Direct Effects of Heat Stress In Vitro. Biol Reprod October v. 71, n. 4, p. 13031308, 2004.

PEIXOTO, M.G.C.D.; BERGMANN, J.A.G.; FONSECA, C.G.; PENNA, V.M; PEREIRA, C.S. Effect of environmental factors on multiple ovulation of zebu donors. Arq. Bras. Med. Vet. Zootec., v. 58, n. 4, p. 567-574. 2006.

PEIXOTO, M.G.C.D., BERGMANN, J.A.G., SUYAMA, E., CARVALHO, M.R.S., PENNA, V.M. Logistic regression analysis of pregnancy rate following transfer of Bos indicus embryos into Bos indicus _ Bos taurus heifers. Theriogenology. v. 67, p. 287-292, 2007.

PIRES, M.F.A. Manejo nutricional para evitar o estresse calórico. A Lavoura. Ed. Sociedade Nacional de Agricultura. Rio de Janeiro. n. Dez. p. 27-30, 2010.

PONTES, J.H.F., SILVA, K.C.F., BASSO, A.C., RIGO, A.G., FERREIRA, C.R.,SANTOS, G.M.G., SANCHES, B.V., PORCIONATO, J.P.F., VIEIRA, P.H.S., FAIFER, F.S., STERZA, F.A.M., SCHENK, J.L. e SENEDA, M.M. Large-scale in vitro embryo production and pregnancy rates from Bos taurus, Bos indicus, and indicus-taurus dairy cows using sexed sperm. Theriogenology v. 74, p.1349-1355. 2010. 
PONTES, J.H.F.; NOTATO-JUNIOR, I.; SANCHES, B.V.; ERENOJUNIOR, J.C.; UVO. S. BARREIROS, T.R.R.; OLIVEIRA, J.A. HASLER, J.F.; SENEDA, M.M. Comparison of embryo yield and pregnancy rate between in vivo and in vitro methods in the same Nelore (Bos indicus) donors cows. Theriogenology, v. 71, n. 4, p. 690-697. 2009.

PRADO, F.R.A., TONIOLLO, G.H.; OLIVEIRA, J.A. Diferentes concentrações de FSH na colheita de embriões em vacas da raça Gir. Revista Cientifica Eletronica de Medicina Veterinária. Ano 4, n. 8, 2007. Acessado em WWW.revista.inf.br/veterinaria08/ artigos/05.pdf em maio 2012.

RIVERA, R.M. and HANSEN, P.J. Development of cultured bovine embryos after exposure to high temperatures in the physiological range. Reproduction v. 121, p. 107-115. 2001.

RUTLEDGE, J .J., MONSON., R .L., NORTHEY, D. L. AND LEIBFRIED-RUTLEDGE, M. L. Seasonality of cattle embryo production in a temperate region. Theriogenology $v .51, p$ 330,1999.

RYAN, D.P.,PRICHARD J.F.,KOPEL,E.,GODKE, R.A.. Comparing early embryo mortality in dairy cows during hot and cool seasons of the year. Theriogenology. v. 39, n. 3, p. 719-37, 1993.

SANTOS, J.C. Dinâmica follicular em bovines da raça Gir no inverno e no verão. Tese (Mestrado). Universidade Federal Fluminense. Niterói, RJ, 93 p. 2001.
SAS. Statistical Analysis Sistem for Windows. SAS Insstitute, Inc, Cary NC, 1994.

SONMEZ, M.S., DEMURCU, E., GAFFARI, T.R.K., SEYFETTIN, G.R. Effect of Season on Some Fertility Parameters of Dairy and Beef Cows in Elazig Province - Turkey. Turk J Vet Anim Sci. v. 29, p. 821-828. 2005.

THATCHER, W.W., FLAMENBAUM, I., BLOCK, J., and BILBY, T.R. Interrelationships of heat stress and reproduction in lactating dairy cows. The High Plains Dairy Conference. Amarillo, Tx. USA. p. 4560. March 2010.

TORRES-JUNIOR, J.R.S. Produção in vitro de embriões em Bos indicus sob estresse calórico. Tese (doutorado). FMVZ. USP. 134 p. 2007.

VISINTIN, J.A., ARRUDA, R.P., MADUREIRA, E.H., MIZUTA, K., CELEGHINI, E.C.C., ASSUNPÇÃO, M.E.O.D., GUSMÕES, P.P.G., CANDINI, P.H. Superovulação de novilhas da raça Nelore com diferentes doses de FSH/LH e congelação de embriões pelo método on-step com etilenoglicol. Braz. J. Res. Anim. Sci. v. 36, n. 5, São Paulo. 1999

WOLFENSON, D., THATCHER, W.W., BADINGA, L., SAVIO, J.D., MEIDAN, R., LEW, B.J., BRAW-TAL, R., BERMAN, A. Effect of heat stress on follicular development during the estrous cycle in lactating dairy cattle. Biology of Reproduction, v. 52, p. 1106-1113. 1995. 